\title{
CULTIVO OTIMIZADO PARA EXTRAÇÃO DE RNA E AMPLIFICAÇÃO DO Cdna DE MONILIOPHTHORA PERNICIOSA (STAHEL) AIME \& PHILLIPS-MORA PARA PARA EXPRESSÃO RECOMBINANTE DE UMA CELULASE
}

\author{
$\underline{\text { Edjane Ferreira }^{1} \text {; Jamille de Santana Melo Adorno }}{ }^{2}$, Luiz Henrique Machado Oliveira ${ }^{3}$; \\ Sandra Aparecida de Assis ${ }^{4}$; Raquel Benevides; \\ 1.Bolsista do Programa de Iniciação Científica da Fundação de Amparo à Pesquisa do Estado \\ da Bahia (PIBIC/FAPESB), Graduanda em Ciências Biológicas, Bacharelado, Universidade \\ Estadual de Feira de Santana, e-mail: edjaniny@ hotmail.com \\ 2. Mestranda em Biotecnologia, Universidade Estadual de Feira de Santana, e-mail: \\ henriquebiomol@gmail.com \\ 3. Mestranda em Biotecnologia, Universidade Estadual de Feira de Santana, e-mail: \\ henriquebiomol@gmail.com \\ 4. Colaboradora, Departamento de Saúde, Universidade Estadual de Feira de Santana (UEFS), \\ e-mail: sandrinhaassis@yahoo.com.br \\ 5. Orientadora, Departamento de Ciências Biológicas (DCBio),Universidade Estadual de \\ Feira de Santana (UEFS), e-mail: raquelgb@gmail.com
}

PALAVRAS-CHAVE: basidiomiceto, enzimas, celulase

\section{INTRODUÇÃO}

A celulose é um polímero de alta abundancia e renovabilidade na terra, sendo uma possível fonte renovável de matéria prima e energia. As celulases, enzimas degradadoras de celulose, são usadas na industria dentre outras utilidades para a bioconversão de bioetanol: FUJITA et al. (2004). Essa enzima está presente em plantas, microrganismos e trato digestivo de animais: HUANG et al., (2008), WATANABE; TOKUDA, (2010). Os fungos necessitam excretar celulases que são responsáveis pela degradação da parede celular vegetal: SATANA (2010). O fungo Moniliophthora perniciosa (Stahel) Aime\& Phillips-Mora, um basidiomiceto causador da vassoura de bruxa, é um conhecido produtor de celulases termoestáveis: SANTANA (2010). Sendo assim, esse estudo propõe uma otimização do protocolo para clonagem dessa enzima que é uma forte candidata à produção recombinante para uso industrial.

\section{MATERIAIS E MÉTODOS}

O Moniliophthora perniciosa isolado foi obtido na Coleção de Culturas de Microrganismos da Bahia (CCMB), localizado na Universidade Estadual de Feira de Santana (UEFS), com o número de identificação CCMB 257, preservado em método Castellani reativado em meio sólido Agar batata e dextrose (BDA) por 15 dias a $25^{\circ} \mathrm{C}$.

Após esse período de incubação o fungo foi inoculado em dois tipos de meios. $\mathrm{O}$ primeiro meio de cultivo (WY) foi produzido com os seguintes componentes: $40 \mathrm{~g}$ de farelo de trigo; $6 \mathrm{~g}$ de extrato de levedura; $1 \mathrm{~g}$ de $\mathrm{K}_{2} \mathrm{HPO}_{4} ; 0,2 \mathrm{~g}$ de $\mathrm{MgSO}_{4} ; 0,2 \mathrm{~g}$ de KCL e água destilada q.s.p. 1L. O segundo meio de cultivo (CMC) foi produzido com os seguintes componentes: $6,0 \mathrm{~g}$ de $\mathrm{K}_{2} \mathrm{HPO}_{4} ; 5,0 \mathrm{~g}$ de carboximetilcelulose; 3,0 g de extrato de levedura; 3,0 g de $\mathrm{KH}_{2} \mathrm{PO}_{4} ; 1,5 \mathrm{~g}$ de Agar; $1,2 \mathrm{~g}$ de $\mathrm{NaNO}_{3} ; 0,2 \mathrm{~g}$ de $\mathrm{MgSO}_{4} 7 \mathrm{H}_{2} \mathrm{O} ; 0,05 \mathrm{~g}$ de $\mathrm{CaCl}_{2}$ $2 \mathrm{H}_{2} \mathrm{O} ; 0,01 \mathrm{~g}$ de $\mathrm{MnSO}_{4} 7 \mathrm{H}_{2} \mathrm{O} ; 0,001 \mathrm{~g}$ de $\mathrm{ZnSO}_{4} 7 \mathrm{H}_{2} \mathrm{O}$ e água destilada q.s.p. 1L. A incubação foi realizada pelo período de 7 a 15 dias em estufa B.O.D a $26^{\circ}$ C.

Após consecutivos repiques do fungo, tornou-se necessário em alguns momentos a reativação em meio de cultivo (Agar batata dextrose) produzido com os seguintes componentes: $200 \mathrm{~g}$ de batata cozida e amassada e $30 \mathrm{~mL}$ de água destilada. A incubação foi 
por um período de 15 dias a $25^{\circ} \mathrm{C}$. Após esse período, foi retirado um disco de $1 \mathrm{~cm}$ de diâmetro e transferido para placas de petri contendo meio liquido WY.

Para extração de RNA, usou-se o reagente TRIZOL (Invitrogen ${ }^{\circledR}$ ) seguindo as recomendações do fabricante, tendo alterações na incubação que o fabricante solicitava a incubação em temperatura ambiente passando a incubar as amostras em baixas temperaturas (utilizando-se gelo ou refrigeradores) durante todo o processo. Para extração foi utilizado ainda o kit de extração (Invitrogen ${ }^{\circledR}$ ) conforme recomendações do fabricante, como método alternativo de obtenção de RNA total.

Após extraído o RNA foi analisado no espectofotômetro NanoDrop 2000/2000c (Thermo Scientific ${ }^{\circledR}$ ) seguindo para a eletroforese em gel de agarose a $0,8 \%$. O resultado foi registrado pelo Transiluminador de ultravioleta L.PIX (Loccus biotecnologia).

Os primers específicos utilizados foram desenhados com base em regiões conservadas entre as sequências gênicas de celulase de basidiomicetos, disponíveis no Genbank (NCBI National Center for BiotechnologyInformation).

Para a síntese do cDNA, foram colocados $8 \mu \mathrm{L}$ de RNA total em microtubos de $0,2 \mathrm{ml}$ contendo $1 \mu \mathrm{L}$ de buffer, $1 \mu \mathrm{L}$ de DNAse I e $8 \mu \mathrm{L}$ de água nuclease free em seguida foi feita a incubação por 15 minutos em temperatura ambiente para a eliminação do DNA genômico na amostra, logo após a amostra foi incubada a $65^{\circ}$ por 15 minutos para inativação da DNAse I.

Para a reação de transcrição reversa, (formação do DNA apartir de um molde de RNA) foi utilizado $5 \mu \mathrm{L}$ do RNA tratado com DNAse I, $3 \mu \mathrm{L}$ de água nuclease free, $1 \mu \mathrm{L}$ OligodT (Invitrogen ${ }^{\circledR}$ ) e $1 \mu \mathrm{L}$ de Desoxirribonucleotideos Trifosfato (dNTPs) a $10 \mathrm{mM}$ e incubou-se a $65^{\circ} \mathrm{c}$ por 5 minutos.

Em seguida adicionou-se $4 \mu \mathrm{L} \mathrm{MgCl}_{2} 25 \mathrm{mM} ; 2 \mu \mathrm{L}$ Tampão RT 10x; $2 \mu \mathrm{L}$ DTT 0,1 $\mathrm{M} ; 1 \mu \mathrm{L}$ RNAse, e incubou-se a $42^{\circ} \mathrm{C}$ por $2 \mathrm{~min}$. No passo seguinte adicionou-se $1 \mu \mathrm{L}$ Super Script II RT a qual foi submetido a nova incubação a $42^{\circ} \mathrm{C}$ por $50 \mathrm{~min}$, em seguida houve a paralização da reação a $70^{\circ} \mathrm{C}$ por $15 \mathrm{~min}$. Para eliminação do RNA foi colocado $1 \mu \mathrm{L}$ RNAse $\mathrm{H}$ e realizada ultima incubação a $37^{\circ} \mathrm{C}$ por 15 min depois armazenado o cDNA sintetizado a $80^{\circ} \mathrm{C}$.

Para amplificação do cDNA foi utilizada a técnica de Reação de Cadeia Polimerase (PCR). Como fita molde foi utilizada a primeira fita de cDNA e, como iniciadores, um dos primers específicos para o gene (como senso) e oligo-dT (Ancor Primer, anti-senso).

A reação foi preparada usando três kits o primeiro Kapa Taq, Biossistems ${ }^{\circledR}$, o segundo Kapa HiFi Hotstart, Biossistems ${ }^{\circledR}$ e o ultimo Taq Platinum Invitrogen ${ }^{\circledR}$ seguindo instruções do fabricante.

A PCR foi realizada no termociclador (BIO-RAD Prime Thermal Cycler). Utilizando o programa especifico a cada kit mudando apenas a temperatura de anelamento que variou de $58^{\circ} \mathrm{C}$ a $60^{\circ} \mathrm{C}$. Após a amplificação foi realizada a eletroforese em gel de agarose a $1,2 \%$. O resultado foi registrado pelo Transiluminador de Ultravioleta L.PIX (Loccus Biotecnologia).

\section{RESULTADOS E DISCUSSÃO}

O fungo Moniliophthora perniciosa inoculado em meio BDA por 15 dias apresentou crescimento satisfatório. Os inóculos em meio liquido WY apresentaram micélio em quantidade suficiente para extração após 14 dias de incubação. O cultivo em meio liquido favoreceu a extração de RNA, pois nesse meio o fungo obteve maior superfície de contato. Segundo Santana (2010), técnicas de cultivo em meio líquido apresentam maiores vantagens para o desenvolvimento fúngico, devido principalmente a interação dos nutrientes com o microrganismo. Já no meio CMC não houve massa micelial de quantidade e qualidade necessária para extração. O cultivo em meio batata foi utilizado para a reativação do fungo quando necessária, garantindo o crescimento. 
As amostras obtidas dos dois protocolos testados para a extração do RNA total analisadas no espectofotometro NanoDrop 2000/2000c (Thermo Scientific ${ }^{\circledR}$ ) apresentaram resultados muito diferentes. $\mathrm{O}$ protocolo com o reagente Trizol obteve uma concentração de ácidos nucléico $0,85 \mathrm{ug} / \mathrm{mL}$, já o com o Kit extração Invitrogen a concentração de ácidos nucléicos foi de $321,8 \mathrm{ug} / \mathrm{mL}$.

Com base nos resultados da extração, o protocolo do reagente Trizol apresentou menor concentração de RNA que o Kit de extração Invitrogen ${ }^{\circledR}$. Levando em conta o resultado da concentração por meio da espectofotometria foi realizada uma nova extração de RNA total usando o protocolo do Kit extração Invitrogen ${ }^{\circledR}$. As amostras com o kit da invitrogen foram submetidas a eletroforese em gel agarose $0,8 \%$, mostrando bandas sem arrasto e com boa nitidez conforme figura 1 .

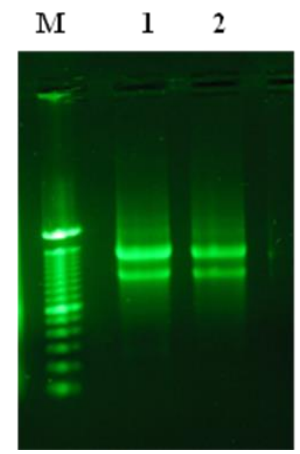

Figura 1- Eletroforese em gel de agarose $0,8 \%$ como resultado da extração de RNA. Da direita para esquerda M: Marcador de massa molecular de 100pb DNA Ladder, amostras 1 e 2 da extração com o kit da invitrogen.

Com base nas sequências obtidas no banco de dados do projeto genoma do $M$. perniciosa sintetizamos 4 melhores primers (IDT DNA), seguindo os parâmetros de temperatura de melting $(\mathrm{Tm})$ que variou de $60^{\circ} \mathrm{C}$ a $63,1^{\circ} \mathrm{C}$ e teor de $\mathrm{C} / \mathrm{G}$ que variou de $52 \%$ a $58,3 \%$ (Tabela 1$)$.

Tabela 1Primers desenhados para amplificação

\begin{tabular}{|l|l|l|l|}
\hline Primers & Sequência $\mathbf{5}^{\prime} \rightarrow \mathbf{3}^{\prime}$ & Teor de C/G & $\begin{array}{l}\text { Temperatura de } \\
\text { melting }(\mathbf{T m}) .\end{array}$ \\
\hline CELase3RACE2 & AGT CCT GGT CGT GGA ATG GGA GAG & $58,3 \%$ & $62,1^{\circ} \mathrm{C}$ \\
\hline CELase3RACE1 & ATT GGG GGT GGA GGA GGT TTC GTG & $58,3 \%$ & $63,1^{\circ} \mathrm{C}$ \\
\hline EndoGIcMpn1 & ATG TTC TAC CGG CTC CTA CTC GTC T & $52,0 \%$ & $60,7^{\circ} \mathrm{C}$ \\
\hline EndoGIcMpn2 & AAG CAT GGT CCG CAC TTT CTC & $52,0 \%$ & $61,0^{\circ} \mathrm{C}$ \\
\hline
\end{tabular}

A amplificação do gene Moniliophthora perniciosa com o uso dos primers desenhados a partir do RNA extraído não apresentou formação de bandas com especificidade, apresentando pouca nitidez e de tamanho inferior do desejado. Na figura 2, pode-se ver que não foi possível amplificar a região de interesse do cDNA sintetizado, aparecendo bandas de baixo peso molecular de aproximadamente 200 pb nas amostras 5 e 7 usando o kit kapa taq.

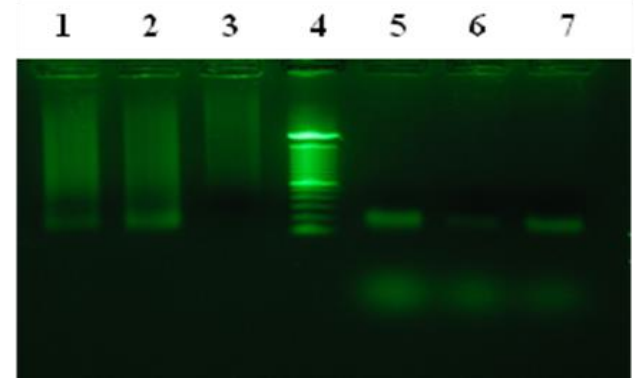


Figura 2: Gel de agarose a 1,2\% com resultado de PCR de $M$. Perniciosa cultivado em meio liquido WY. Da direira para esquerda: amostra 1: kit taq platinum, temperatura $58^{\circ} \mathrm{C}$, primer EndoGlcMpn1, amostra 2: kit taq platinum, temperatura $60^{\circ} \mathrm{C}$, primer EndoGlcMpn 1 , amostra 3: kit taq platinum, temperatura $60^{\circ} \mathrm{C}$, primer CELase3RACE1, amostra 4: Marcador de massa molecular de 100pb DNA Ladder, amostra 5: kit Kapa Taq, temperatura $60^{\circ} \mathrm{C}$, primer EndoGlcMpn1, amostra 6: kit Kapa Taq, temperatura $60^{\circ} \mathrm{C}$, primer CELase3RACE1, amostra 7 : kit Kapa Taq, temperatura $58^{\circ} \mathrm{C}$, primer EndoGlcMpn1.

Mesmo com 4 primers desenhados e usando 3 kits para a reação a amplificação não foi como esperada. Diante desses resultados, podemos levantar duas hipóteses: o fungo está expressando pouco o gene da celulase nos meios indutores utilizados, dessa forma produz pouco RNA mensageiro referente a enzima em questão, ou os primers desenhados não se anelaram adequadamente com o cDNA sintetizado. Novas condições de cultivo e de amplificação estão em teste.

\section{CONCLUSÃO}

Com base nos resultados alcançados, o meio liquido WY proporcionou um desenvolvimento de massa micelial e de material para extração de forma satisfatória. Para a extração o kit da invitrogen comparado ao reagente Trizol foi o que houve melhor resultado. Até o momento, os meios de cultivo utilizados e condições de amplificação não geraram o inserto esperado. Tem-se proposto novas condições de cultivo do fungo, que induzam a expressão do gene de interesse, assim como o teste de novos primers e variações de condições de amplificação como temperatura de anelamento.

\section{REFERÊNCIAS}

AIME M. C., PHILLIPS-MORA, W. 2005. The causal agents of witches' broom and frosty pod rot of cacao (chocolate, Theobroma cacao) from a new lineage of Marasmiaceae.

Mycologia, v97, n5, p1012-1022.

FUJITA, Y.; ITO, J.; UEDA, M.; FUKUDA, H.; KONDO, A.2004. Synergistic saccharification, and direct fermentation to ethanol, of amorphous cellulose by use of an engineered yeast strain codisplaying three types of cellulolytic enzyme. Appl. Environ. Microbiol. 70, 1207-1212.

HUANG, H.; YANG, P.; LUO, H.; TANG, H.; SHAO, N.; YUAN, T.; WANG, Y.; BAI, Y.; YAO,.2008. B.High-level expression of a truncated 1,3-1,4- $\beta$-D-glucanase from Fibrobacter succinogenes in Pichia pastoris by optimization of codons and fermentation. Appl. Microbiol. Biotechnol. 78, 95-103.

SANTANA, M. L.2010. Produção, caracterização, aplicação e determinação estrutural de celulase de Moniliophthora perniciosa. Dissertação apresentada ao Programa de Pósgraduação da Universidade Estadual de Feira de Santana, Bahia.

WATANABE, H.; TOKUDA, G.2010. Cellulolytic systems in insects. Annu. Rev. Entomol. $55,609-632$. 